\title{
Hidrops no inmune de resolución espontánea -Presentación de un caso-
}

\author{
Emilio Alberto Restrepo Baena*
}

\begin{abstract}
RESUMEN: Se presenta el caso de una paciente que presentó un diagnóstico ecográfico de Hidrops Fetal no Inmunológico durante el segundo trimestre de la gestación, del cual no se pudo precisar nunca la causa y que se resolvió espontáneamente sin secuelas dando como resultado un PVE de una niña normal. Se revisan las causas más frecuentes.
\end{abstract}

PALABRAS CLAVES: Hidrops fetal no inmune. Resolución espontánea. Seguimiento ecográfico.

SUMMARY: We show a patient story with echographical diagnosis of Nonimmune Fetal Hydrops in the pregnancy half. We never knew about of the Hydrops ethiology, but this was spontaneously resolved without consequences for the child. We review the most commun causes.

KEY WORDS: Nonimmune fetal hydrops. Spontaneous resolution. Echographical following.

\section{Sra S. L. C. HC 1326561 del HUSVP}

Paciente de 28 años, casada, oficios domésticos. G4, P3, $\mathrm{M} 2, \mathrm{~A} 0$, V1. (El primero Anencefálico, el segundo murió por SFA intraparto, al parecer por accidente relacionado con tres circulares de cordón apretadas a cuello. Aspecto normal del feto, sin malformaciones. El tercero, PVE normal, vivo actualmente).

A las 13 semanas ingresa a ARO por sus antecedentes y porque una ecografía reporta Placenta Previa Total. A las 23 semanas la ecografía de control dice que la placenta es Previa Parcial. Nunca ha presentado sangrado vaginal ni síntoma alguno.

A las 29 semanas un nuevo control ecográfico reporta Ascitis y Derrame Pericárdico, con una placenta no previa de $5.8 \mathrm{~cm}$ de espesor. Un control a las 30 semanas muestra aumento de volumen de líquido amniótico, edema de piel de $4.5 \mathrm{~mm}$, derrame pericárdico, ascitis fetal. Las cuatro cavidades cardíacas de tamaño normal, paredes normales. No defectos del tubo neural.

Una ecografía del tercer nivel encuentra Placenta Grado I, no previa, edematizada, con un grosor de $7.5 \mathrm{~cm}$; líquido amniótico aumentado de tamaño; cabeza, cara y cuello normales; tórax, con derrame pericárdico de $5 \mathrm{~mm}$, FCF 140 sin arritmias, dimensiones, paredes y septos del corazón normales. Dopler pulsado normal.

Abdomen: edematizado, ascitis severa. TGI se visualiza normalmente, riñón y vejiga normales. Perímetro abdominal $33.7 \mathrm{~cm}$. Extremidades y columna normales. Hacen Diagnóstico de Hidrops no inmune, no cardigénico.

\footnotetext{
* Médico y Cirujano egresado de la Facultad de Medicina de la U.P.B. en Medellín.

Actualmente cursando estudios de postgrado en obstetricia y ginecología en la Universidad de Antioquia. Residente de II año.
}

El control ecográfico de las 34 semanas reporta desaparición de los signos de hidropesía fetal, líquido amniótico y placenta normales. No hipoplasia pulmonar, todos los órganos normales.

Se continúan haciendo controles ecográficos que muestran un feto normal, sin signos de Hidrops, creciendo en un percentil adecuado, con placenta y líquido proporcionados para la edad gestacional.

El examen físico siempre es normal. No hay evidencia de enfermedades virales del tracto respiratorio, del TGI o de la piel. La presión arterial es normal. Nunca hay fiebre. No hay hiperemesis gravídica. No hay edemas.

Informes de laboratorio: Anticuerpos Anti Toxoplasma IgM, Negativos. Anticuerpos Anti Rubeola, Negativos. VDRL, Negativo.

Tamisaje O'Sullivan Negativo. Anticuerpos antinucleares, Negativos. Grupo Sanguíneo O Positivo. Esposo O Positivo.

Hb: 13.7 Hto: 41.2 GB: 9.300 PMN $67 \operatorname{Linf} 27$

Urocultivos negativos, Cooms Indirecto Negativo.

NST: siempre reactivos. CST, siempre negativos.

A las 40 semanas se obtiene por PVE una niña de $3550 \mathrm{gr}$, $51 \mathrm{~cm}$ de talla, 35.5 de PC, 35.5 de PT. Apgar 9 al min, 10 a los $5 \mathrm{~min}$.

Activa, sin SDR, fontanela normal, sin cataratas. Sin ictericia.

Cabeza y cuello normales. Corazón sin soplos, rítmico. Abdomen sin masas ni megalias, sin ascitis, cordón normal, 2 arterias, 1 vena. Ano normal, Neurológico y piel normal. Ortopédico y genitales normales. EKG, leído como normal. $\mathrm{Hb}: 17$ Grupo O positivo.

$\mathrm{Al}$ mes, la niña continúa en perfectas condiciones.

El problema del Hidrops no inmune en nuestro medio no está cuantificado ni estudiado. En otras latitudes el uso de la profilaxis efectiva contra la isoinmunización $\mathrm{Rh}$ ha desplazado la proporción de Hidropesias inmunológicas que antes eran 
muy abundantes (hasta el 80\%), a sólo un 10\% $(1,2)$. Según Acuña, en nuestro medio, cerca de la mitad corresponden a patología inmune, por isoinmunización; un 17\% se considera idiopático y un $37 \%$ tienen diferentes etiologías o por lo menos asociaciones (3). Del Hidrops no inmune que nos ocupa, del 50 al $80 \%$ tienen un pronóstico fatal $(2,3,5)$. El $75 \%$ se asocia a Polidramnios, $(2,4,5)$, del 15 al $45 \%$ se asocian a preeclampsia $(4,6)$ de 7 a $67 \%$ presentan algún grado de anemia $(4,6)$. Con menos frecuencia hay asociación con diabetes gestacional o infección urinaria $(2,4,6)$. En la Tabla 1 se aprecian las principales entidades que causan o se asocian a Hidrops no inmunológicos; algunas son susceptibles de intervención intraútero (por técnicas invasivas, complejas, costosas y no siempre disponibles en nuestro medio) y otras lo son una vez nacido el niño $(1,4,7,10)$.

\section{Figura 1}

IMAAGEN ECOGRAFICA DEL DERRAME PERICARDICO EN RESOLUCION

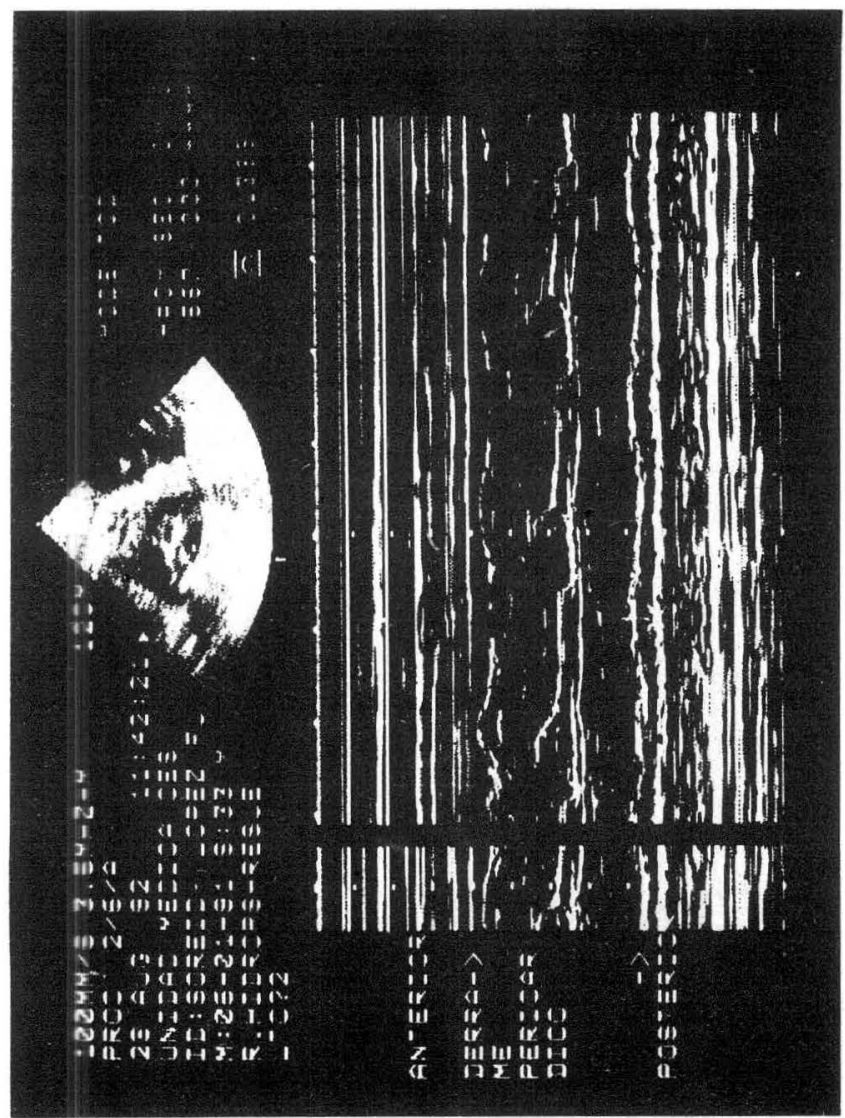

El pilar del diagnóstico, seguimiento y tratamiento es la ecografía, que también auxilia otros métodos invasivos como la amniocentesis, la cordocentesis, la cirugía intraútero, las transfusiones, etc. El Dopler puede tener alguna utilidad como auxiliar de diagnóstico y seguimiento.

Es importante tener en cuenta que pese al mal pronóstico del Hidrops no inmunológico, se han reportado varios casos de resoluciones espontáneas, como en el caso que discutimos $(2,7-9)$. Debido a las limitaciones, sobre todo recursos y tecnología, nunca fue posible definir su etiología. Aventuramos que podría circunscribirse dentro de ese 17 a $20 \%$ clasificado como "idiopático" $(2,3)$.
Tabla 1

ENFERMEDADES CAUSANTES Y ASOCIADAS A HIDROPS NO INMUNE (1-6)

Anemia fetal

Alfatalasemia homocigótica

Deficiencia de G6PD

Síndrome de poliesplenia fetal

Alteraciones cardiovasculares fetales

Bloqueos cardíacos

Taquiarritmias

Embolia arterial coronaria

Defectos anatómicos de paredes, septos y válvulas Miocardiopatías (virales?)

Tumores intracardíacos

Embarazo gemelar (transfusión fetal, cortocircuitos)

Alteraciones renales

Infecciones congénitas

TORCH

Hepatitis

Virus Coxsackie

Rubeola

Enfermedad de Chagas

Leptospirosis

Parvovirus B 19

Enfermedad materna

Diabetes mellitus severa

Anemia severa

Hipoproteinemia

Alteraciones Torácicas

Hernia diafragmática

Hipoplasia pulmonar

Obstrucción o ausencia del conducto torácico

Tumores congénitos

Alteraciones del tracto gastro intestinal

Atresia yeyunal

Vólvulo intestinal

Peritonitis por meconio fetal

Causas cromosómicas

Síndrome de Down

Síndrome de Turner

Trisomía del 18

Otras causas

Enanismo tanatofórico

Artrogrifosis

Osteogénesis imperfecta

Traumatismo fetal

Atresia biliar

Cirrosis familiar

Torsión del cordón umbilical o nudos de éste

Trombosis placentaria

Aneurisma de la arteria umbilical

Quiste torcido de ovario fetal

Hidrotórax congénito 


\section{BIBLIOGRAFIA}

1. Warsof Nicolaides, et al. Inmune and Nonimmune Hydrops. Clin. Obstet. Gynecol. 1986; 29: 533.

2. Callen Peter. Ecografía en obstetricia y ginecología. Cap. 12 "Evaluación de la Hidropesía Fetal" 2 ed. Buenos Aires, Panamericana, 1991; 285-303.

3. Acuña, Juan Manuel. Manejo del Hidrops Fetal. En Mimeo.

4. Graves GR, Basket TF. Noimmune Hidrops Fetalis: Antenatal Diagnosis and Management. Am. J. Obstet. Gynecol. 1984; 148: 566.

5. Hutchison A. et al. Nonimmunologic Hidrops Fetalis: A review of 61 cases. Obstet. Gynecol. 1982; 59: 247.

6. IM. Ss et al. Nonimmunologic Hidrops Fetalis. Am. J. Obstet. Gynecol. 1984; 148: 566.
7. Watson J. Campbell. Antenatal Evaluation and Management in Noimmune Hidrops Fetalis. Obstet. Gynecol. 1986; 67: 589.

8. Mueller-Heuback E. Mazer. Sonographically documented disapperearance of Fetal Ascites. Obstet. Gynecol. 1983; 61: 253.

9. Humprey Wendy et al. Severe Nonimmune Hidrops Secondary to Parvovirus B-19 infection: Spontaneous reversal in uterus and survival of a term infant. Obstet. Gynecol. 1991; 78: 900.

10. Castillo RA. et al. Noimmune Hydrops Fetalis: Clinical Experience and factor related to a poor outcome. Am. J. Obstet. Gynecol. 1986; 155: 812 . 